\title{
Como formadores e alunos da licenciatura em Letras compreendem a linguística aplicada?
}

How do educators and student teachers

from a language education course understand applied linguistics?

Wagner Rodrigues Silva*

Universidade Federal do Tocantins - UFT

Palmas - Tocantins / Brasil

Cristiane Carvalho de Paula Brito**

Universidade Federal de Uberlândia - UFU

Uberlândia - Minas Gerais / Brasil

Renato Goveia Martins ${ }^{* * *}$

Universidade Federal do Tocantins - UFT

Araguaína - Tocantins / Brasil

Sandra Alves dos Santos ${ }^{* * * *}$

Universidade Federal do Tocantins - UFT

Araguaína - Tocantins / Brasil

RESUMO: Nesta pesquisa, (i) investigamos compreensões de formadores e professores em formação inicial acerca da linguística aplicada (LA), no contexto de uma Licenciatura em Letras e (ii) problematizamos alguns desdobramentos dessas compreensões para o ensino e a aprendizagem de línguas e a formação de professores. Os resultados apontam que a LA é concebida, pelos professores formadores, como: subárea da linguística; disciplina mediadora entre teoria e prática; área não disciplinar; ou disciplina autônoma com foco na linguagem. Para os professores em formação inicial, a compreensão acerca da LA é mais rudimentar, sendo desconhecida para a maioria desses colaboradores, da

\footnotetext{
*wagnerodriguesilva@gmail.com

** carvalhodepaula@yahoo.com

*** regoveia7@gmail.com

****sandraasantos1@hotmail.com
} 
mesma maneira que, para outros, além de ser confundida com a linguística, é caracterizada pelo estudo da gramática da língua ou, até mesmo, por abordagens investigativas não disciplinares.

PALAVRAS-CHAVE: Currículo; epistemologia; formação de professores.

ABSTRACT: In this research, we (i) investigated comprehension of language teacher educators and pre-service language teachers concerning applied linguistics (AL), in the context of a language teacher education course and (ii) we problematized some implications of such comprehension for both the teaching and learning of languages and for the language teacher education. Results suggest that AL is conceived by language teacher educators as a subfield of linguistics; a discipline which mediates theory and practice; a non-disciplinary area; or as an autonomous discipline with focus on language. For pre-service language teachers, comprehension of AL is more rudimentary, not even known by most of the participants, in the same way that, for others, besides being confused with linguistics, AL is characterized as the study of the grammar of a language or even as a non-disciplinary investigative approaches.

KEYWORDS: Curriculum; epistemology; language teacher education.

\section{Introdução}

A discussão acerca da natureza da linguística aplicada (LA), tanto no cenário brasileiro quanto internacional, não é recente, como se pode observar em publicações a respeito do paradigma científico que configura esse campo de estudos (CORACINI; BERTOLDO, 2003; FORTKAMP; TOMITCH, 2008; FREIRE; ABRAHÃO; BARCELOS, 2005; GONÇALVES; SILVA; GÓIS, 2014; HALL; SMITH; WICAKSONO, 2011; MOITA LOPES, 2013a; 2006a; PENNYCOOK, 2001; SIGNORINI; CAVALCANTI, 1998). Esse fato revela não somente a temporalidade da discussão como também a intensidade do fato na comunidade científica.

Neste artigo, (i) investigamos compreensões que formadores e professores em formação inicial, em uma Licenciatura em Letras, compartilham acerca da LA; e (ii) problematizamos alguns desdobramentos dessas compreensões para o ensino-aprendizagem de línguas e a formação de professores. Esta pesquisa se justifica por inquietações existentes na comunidade acadêmica no tocante à percepção de contribuições da LA para a formação inicial de professores de língua nas licenciaturas brasileiras. ${ }^{1}$

\footnotetext{
${ }^{1}$ Este artigo retoma resultados de pesquisa reunidos previamente nos estudos de Martins (2015) e Santos (2015), contribuindo para as investigações científicas desenvolvidas no grupo de pesquisa Práticas de Linguagem - PLES (UFT/CNPq).
} 
Para desenvolver nossa proposta, organizamos este artigo em três partes, além desta introdução e das referências ao final do texto: na primeira, discutimos a natureza da LA, levando em consideração seus deslocamentos conceituais, a partir das vozes de alguns linguistas aplicados atuantes no contexto acadêmico brasileiro. Em seguida, passamos à descrição do percurso metodológico desenvolvido para este estudo e à discussão da análise dos dados, pontuando algumas considerações relativas às contribuições da LA para os processos de ensino-aprendizagem de línguas e de formação de professores. Finalmente, tecemos algumas considerações sobre os desdobramentos dos resultados de pesquisa produzidos para os processos mencionados.

\section{Construção paradigmática da LA}

Para explicitar alguns pressupostos teóricos caracterizadores da LA, apresentamos algumas visões de linguistas aplicados brasileiros tomados como referência nesta pesquisa, os quais não só foram influenciados por estudiosos estrangeiros como influenciaram a construção paradigmática da LA além das fronteiras nacionais. ${ }^{2}$ Nosso intuito é ressaltar os deslocamentos que marcam a concepção de LA, bem como o fazer científico do campo de estudos aplicados nas visões dos estudiosos selecionados, além de problematizar a incidência desses estudos nas vozes dos formadores e de professores em formação inicial numa licenciatura em Letras. Desse modo, pontuamos algumas concepções de LA, no período entre a década de 1990 e os anos 2000, encontradas nos trabalhos de Celani (2008, 1998, 1992), Moita Lopes (2013b, 1999, 1998, 1996) e Kleiman (2013, 2002, 1998).

\subsection{Linguística aplicada na década de 1990}

Precursora e fundadora do primeiro Programa de Estudos PósGraduados em Linguística Aplicada do país (PUC-SP), Maria Antonieta Alba Celani publica, em 1992, um capítulo em que explora algumas das interpretações comumente encontradas para a LA. A primeira concepção trata da "noção de LA como sinônimo de estudo científico dos princípios

\footnotetext{
${ }^{2}$ A necessidade de limitar o número de estudiosos mobilizados para esta pesquisa não implica na omissão das contribuições produzidas por outros linguistas aplicados brasileiros igualmente responsáveis pelo desenvolvimento da LA no território brasileiro e, até mesmo, no exterior.
} 
e da prática do ensino/aprendizagem de língua estrangeira" e materna (CELANI, 1992, p. 17). Para a autora, essa concepção restringe o papel do linguista aplicado ao alicerce no qual a área se firmou. A segunda concepção, mencionada e refutada criticamente, que compreende a LA como consumo de teorias, é encontrada, segundo a autora, em Halliday, McIntosh e Strevens (1964) que informam que a LA usa as descrições linguísticas para outras finalidades; aqui encontramos a LA como aplicação de teorias produzidas na linguística, ou seja, a LA seria uma disciplina "que usa os resultados de estudos teóricos para o ensino de línguas" (CELANI, 1992, p. 18).

Alinhada ao posicionamento da autora, a terceira concepção define a LA como área interdisciplinar por meio de algumas metáforas. A construída por Pap (1972) afirma que a LA "é uma encruzilhada, uma ponte com tráfego nos dois sentidos"; enquanto a de Buckingham (1980) se refere à LA como "horizontal, com intersecções”. Em diálogo com Kaplan (1980), Celani compara a LA com o teatro: do mesmo modo como o teatro é o ponto em que todas as artes - música, literatura, cenografia, interpretação, dança, artes plásticas - se encontram e se tornam realidade, "a LA constitui o ponto no qual todo o estudo da linguagem se encontra e se torna realidade" (CELANI, 1992, p. 19-20).

Em resposta ao questionamento que intitula o capítulo "Afinal, o que é linguística aplicada?”, Celani (1992) rescinde a posição central da linguística teórica dentro dos estudos da LA, e aborda dois aspectos que auxiliam na definição do modo de se fazer pesquisa em LA: a necessidade de (i) se fazer LA sem se posicionar inferiormente à linguística; e de (ii) desenvolver trabalhos alinhados à natureza humanista da área.

Em 1998, Celani produz um capítulo no qual coloca para a LA outro modo de produzir conhecimento - o transdisciplinar -, retomando e reformulando a metáfora da ponte com tráfego nos dois sentidos: "a dupla mão de direção no tráfego se aplica, frequentemente, a várias pontes e não só a uma [LA $\leftrightarrow$ linguística]" (CELANI, 1998, p. 131). Depois de caracterizar a transdisciplinaridade como uma atividade que envolve mais que a mera justaposição de saberes, e de observar a área como uma resposta direta às necessidades sociais, a autora esclarece o seu novo modo de entender a LA: uma área de abordagem transdisciplinar, na qual há a disposição para a troca, ajuda e cooperação.

Em abordagem conceptual de 1996, Luiz Paulo Moita Lopes transparece a preocupação de representar o desenvolvimento emergente 
da área naquele momento. $\mathrm{O}$ autor defende que a discussão proposta no trabalho - definir a LA como campo de investigação - deve ser ensaiada, e que tal ação pode contribuir com o desenvolvimento e fortalecimento do sítio. O autor faz comparação da LA vista, no passado, como subárea da linguística e, no presente, em que é reconhecida a autonomia das atividades.

Conforme Moita Lopes (1996, p. 19), a LA se caracteriza por: ter natureza aplicada em ciências sociais (focando a resolução de problemas de uso da linguagem); priorizar a linguagem em seu aspecto processual; possuir caráter interdisciplinar e mediador; envolver formulação teórica; e fazer uso de métodos positivistas e interpretativistas de investigação.

Em "A transdisciplinaridade é possível em linguística aplicada?”, Moita Lopes (1998) faz um estudo acerca da possibilidade de se fazer LA segundo a investigação transdisciplinar, encorajando o linguista aplicado a procurar "subsídios em várias disciplinas que possam iluminar teoricamente a questão em jogo” (MOITA LOPES, 1998, p. 114). Essa visão dialoga, em parte, com a mesma apresentada no texto de 1996. É notável também a oposição do autor à atuação dentro dos limites de uma disciplina teórica e ao entendimento da LA como subárea da linguística.

Ao responder à pergunta título do capítulo, Moita Lopes (1998) destaca como atividades características dos linguistas aplicados (a) a preocupação crescente com o estudo das pessoas em ação no mundo; (b) a troca de informação entre prática e teoria, na qual a descoberta e a aplicação são desenvolvidas conjuntamente; (c) a preocupação com o retorno dos resultados para a prática social, ou seja, para os colaboradores ou participantes de pesquisa; (d) o foco na resolução de problemas específicos; (e) a consciência de uma realidade complexa a ser pesquisada; e (f) a responsabilidade social e divulgação dos resultados que se resume ao questionamento: como é que a pesquisa em LA pode mudar a prática social?

Angela B. Kleiman (1998), por sua vez, ao expor sua crítica aos que se denominam "linguistas aplicados" que, porém, têm vocação para a aplicação linguística, chama a atenção para a necessidade de se desvencilhar a LA da linguística. Para a autora, essa noção de dependência implica numa "concomitante redução da LA ao campo de aplicação e de validação de teorias, modelos ou generalizações de outras disciplinas ou subdisciplinas" (KLEIMAN, 1998, p. 54).

Em síntese, segundo a autora, a LA é uma área heterogênea que focaliza questões que contribuem para o entendimento da complexidade 
da linguagem. A heterogeneidade da LA, contudo, não é entendida como produto de uma não definição do objeto ou objetivo, mas pela quantidade de disciplinas/áreas que se fazem necessárias à pesquisa. Para a autora, essa expansão de horizontes é desejável à medida que representa uma área que se ocupa de questões complexas de investigação científica.

\subsection{LA a partir de 2000}

No capítulo de 2008, Celani destaca a relevância da LA na formação de uma política educacional. São apresentadas algumas das áreas de pesquisas em LA, as quais contribuem para a caracterização desse campo de estudos aplicados. A autora entende a LA como articuladora de múltiplos domínios do conhecimento que têm preocupação com a linguagem, como, por exemplo, a de verificar o "impacto das forças sociais, econômicas e políticas na teoria/prática de ensino/aprendizagem de línguas" (CELANI, 2008, p. 20).

Moita Lopes (2013b) faz uma revisão da área a partir de um campo específico - estudo/aprendizagem de línguas na sala de aula -, apontando, em primeira instância, uma convergência de produção de conhecimento e política como própria da LA ou, como denomina, da LA do emergente. Segundo Moita Lopes (2013b, p. 233), tal LA

prefere/faz opções intencionais por estudar questões, significados e discursos latentes na sociedade e, assim fazendo, traz à tona não as grandes narrativas, mas as pequenas histórias dos entrelugares da vida social, que, longe da significância estatística, podem apresentar alternativas para nosso presente, adiantando o futuro, por assim dizer, e se tornando decisivas para uma vida social mais justa e ética.

No texto, Moita Lopes (2013b) discute a própria pesquisa sobre discurso e identidades/performances de gênero, sexualidade e raça em contextos de letramentos escolares, divulgando, assim, a ampliação do leque de interesse da LA no Brasil. Em sintonia com as teorias queer, o autor caracteriza a pesquisa desenvolvida por ele pela "posição de crítica à noção de legitimidade identitária” (MOITA LOPES, 2013b, p. 237), fundada no pensamento de que o que não é natural ou legítimo são fundações discursivas. Dessa forma, Moita Lopes (2013b) apresenta uma concepção de LA articulada à noção indisciplinar, construída a partir de trabalhos com 
outras lógicas, que contrariam as visões ocidentalistas; e ao estudo de "aspectos microssociais na interação (locais) que mobilizam discursos macrossociais (cada vez mais translocais, em nossos tempos)" (MOITA LOPES, 2013b, p. 235).

Ao ensaiar uma comparação entre a sociolinguística variacionista (SV) e a linguística aplicada brasileira, ele enfatiza o empenho da segunda na construção de conhecimentos inovadores sobre o estudo das relações entre linguagem e vida social ou entre linguagem e identidade/performances. Em contrapartida, o autor argumenta sobre um diagnóstico: a inadequação dos dados da SV, quando confrontados em um estudo etnográfico, a qual se origina de marcadores de frequência de variantes específicos incoerentes com a interação contemporânea.

No capítulo de Kleiman de 2002, captamos os princípios do trabalho do linguista aplicado a partir de questões éticas. Conforme a autora, em diálogo com a abordagem de pesquisa qualitativa delineada por Mason (1996), o linguista aplicado redimensiona e reelabora os referenciais teóricos ou metodológicos dos vários campos de estudo que buscam interpretar o mundo social, apoiando-se em metodologias que levam em conta o contexto em que os dados são gerados e que procuram compreender esses dados e seus contextos em toda sua riqueza, complexidade e profundidade.

Kleiman (2002) destaca ainda a tradição de pesquisa crítica, ou seja, que não procura apenas descrever o fato, mas que também oferece encaminhamentos e soluções para os problemas estudados. Acrescenta-se ainda o enfoque híbrido, ou seja, inter/multidisciplinar e o posicionamento ético anterior à emergência do problema. Segundo a autora, a prática do linguista aplicado parte do princípio de que a responsabilidade do pesquisador é, acima de tudo, para com os indivíduos que estuda e, por consequência, o pesquisador tem o dever de fazer tudo que estiver ao seu alcance para proteger e promover a integridade física, social e psicológica dos grupos estudados (KLEIMAN, 2002). Desenvolvida a partir da contraposição entre LA e linguística, a autora conclui a abordagem enfatizando a necessidade de se fazer uma contribuição crítica para o debate social. Essa atividade integra a identidade do linguista aplicado.

Em 2013, Kleiman apresenta um balanço da agenda de pesquisa e ação na LA. Partindo de uma breve descrição do percurso da LA no Brasil, a autora defende uma abordagem teórico-metodológica que contemple as 
chamadas "vozes do Sul". ${ }^{3}$ A expressão se refere, em síntese, aos saberes trazidos por outras vozes, "à margem do eixo euro-norte-americano de produção de conhecimento" (KLEIMAN, 2013, p. 41).

Considerando alguns dos princípios desenvolvidos no Programa de Modernidade/Descolonialidade (PM/D), "no qual sociólogos, semioticistas, filósofos e historiadores realizam pesquisa que não é 'sobre' a periferia, mas 'a partir da' periferia” (KLEIMAN, 2013, p. 43), a autora defende

uma Linguística Aplicada crítica com uma agenda que, em consonância com sua vocação metodológica interventiva, rompa o monopólio do saber das universidades e outras instituições que reúnem grupos de pesquisadores e intelectuais e toma como um de seus objetivos a elaboração de currículos que favoreçam, por um lado, a apropriação desses saberes por grupos na periferia [...] e, por outro, a legitimação dos saberes produzidos por esses grupos. (KLEIMAN, 2013, p. 42)

Dessa forma, Kleiman (2013) defende para a LA o trabalho com a diversidade, a mudança e a abertura para a renovação paradigmática, a qual contempla sistemas de conhecimentos produzidos por sujeitos à margem, posicionados criticamente em relação à hegemonia de pesquisa. Para a autora, a LA, em sua dimensão ética, tem por objetivo "pensar de outro modo, em direção à outra lógica” (KLEIMAN, 2013, p. 47).

\section{LA no contexto de uma licenciatura em Letras}

Passamos agora a discutir algumas compreensões que professores formadores e em formação inicial têm acerca da LA. Esta pesquisa ocorreu em uma licenciatura em Letras com habilitações em Língua Portuguesa e em Língua Inglesa, em uma universidade pública brasileira, no interior do mais jovem estado do país, Tocantins. ${ }^{4} \mathrm{O}$ curso está vinculado diretamente ao Programa de Pós-Graduação em Letras: Ensino de Língua e Literatura (mestrado e doutorado), que, como o próprio nome nos leva a compreender,

\footnotetext{
3 Tal metáfora é trabalhada por Moita Lopes (2006a), a partir de Boaventura de Sousa Santos, a fim de chamar atenção para a necessidade de se repensar outro sujeito para a LA, de forma que a problematização da vida social não ocorra sem a consideração daqueles que nela vivem. Kleiman (2013), nesse sentido, retoma a discussão.

${ }^{4}$ Para detalhes a respeito da proposta curricular da licenciatura, consultar o trabalho de Silva e Pereira (2016).
} 
enfatiza pesquisas acadêmicas voltadas para o ensino e para a formação de professores de língua e de literatura. Num segundo momento, pretendemos expandir esta pesquisa para outras licenciaturas em diferentes regiões do Brasil.

\subsection{Compreensões da LA por professores formadores}

Para a investigação das compreensões compartilhadas pelos formadores acerca da LA, partimos da hipótese de que há um considerável desconhecimento quanto às áreas de atuação do linguista aplicado, o que pode produzir um sentimento de irrelevância dessa ciência para a formação inicial de professores em algumas licenciaturas. O currículo disciplinar de licenciaturas pode, em determinados aspectos, mostrar-se incompatível com as políticas educacionais atualmente promovidas que visam a melhores resultados no ensino-aprendizagem de línguas na escola brasileira de ensino básico, assim como com os paradigmas atuais que consideram a linguagem como uma prática socialmente construída.

Os dados foram gerados a partir de um questionário, com as seguintes perguntas: (1) Como você define a linguística aplicada?; (2) Como você define a linguística?; e (3) Quais são as principais contribuições das disciplinas ministradas por você na licenciatura em Letras para a formação inicial de professores? Salientamos que os participantes foram orientados a não utilizarem fontes de pesquisas para responder ao questionário isoladamente para devolução em momento posterior ou junto do pesquisador, quando os participantes disponibilizavam de tempo para responder prontamente ao questionário.

Na primeira pergunta, buscamos identificar a compreensão de LA compartilhada por cada formador. $\mathrm{Na}$ segunda, por sua vez, além de identificar a compreensão de linguística, procuramos entender se há uma possível relação ou confusão conceptual entre LA e linguística. Por fim, a terceira foi elaborada com o propósito de diagnosticar a articulação entre as contribuições teóricas e as demandas da prática da formação na área de atuação profissional dos colaboradores, uma das principais preocupações e contribuições da LA.

Os 26 formadores integrantes do corpo docente da licenciatura focalizada, das mais diferentes áreas (LA, linguística, literatura e educação), foram procurados para contribuir para a pesquisa, inclusive os com alguma licença e que, portanto, não estavam atuando durante a realização da geração 
dos dados. Tivemos dezessete participantes que responderam, deixando ou não em branco algumas das questões; e nove rejeições à participação.

As respostas ao questionário foram elencadas em categorias conceptuais e quantificadas no Gráfico 1 para identificar a proporção de cada compreensão categorizada. Como essas categorias são dinâmicas (conforme representado no Gráfico 2), podendo, portanto, um formador expressar mais de uma compreensão categorizada - e dada a impossibilidade do Gráfico 1 representar tal dinamismo -, tivemos de optar por uma categoria para cada participante. $\mathrm{O}$ critério de escolha teve por base o aspecto que, a nosso ver, pareceu mais relevante em cada resposta.

As categorias estão representadas em números, da seguinte forma: (1) LA entendida como subárea da (ou entendida como) linguística; (2) LA entendida como mediadora entre teoria e prática; (3) LA como área inter/pluri/multi ou transdisciplinar; (4) LA como área autônoma com foco na linguagem em contextos; e (5) resposta em branco ou "prefiro não responder". O primeiro número/categoria apresentado (em casos em que há mais de um/uma) se refere à categoria por nós utilizada no Gráfico 1.

\title{
GRÁFICO 1
}

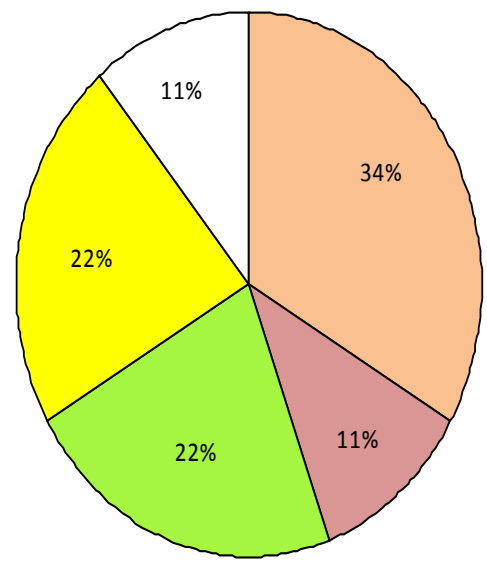

\author{
口LA COMO SUBÁREA DA \\ LINGUÍSTICA \\ $\square$ LACOMO MEDIADORA ENTRE \\ TEORIA E PRÁTICA \\ 口LA COMO ÁREA \\ INTER/PLURI/MULTI OU \\ TRANSDICIPLINAR \\ 口LA COMO ÁREA AUTÔNOMA \\ DRESPOSTAS EM BRANCO
}

As respostas em branco, o registro de "prefiro não responder", e a negação de participação por alguns docentes servem como dados analíticos. 
Desse modo, podemos interpretar a falta de disposição para responder a algumas questões ou a rejeição da pesquisa relacionando-a a alguns aspectos: (a) à natureza da investigação, que, mesmo esclarecidos os objetivos, segundo os participantes, não compete a suas atuações (o que é relevante, pois, por exemplo, é pouco provável, porém necessário, que os estudos de literatura e educação envolvam a LA); (b) às questões propostas, que, segundo alguns, remetem a temáticas conflitantes (o que pode indicar um conhecimento a respeito das questões que envolvem LA e Linguística); (c) ou a algum tipo de constrangimento de qualquer natureza, como, por exemplo, em certos casos, a divulgação de um desconhecimento quanto à LA ou linguística, mesmo sob a égide do anonimato, uma vez que os pesquisadores têm acesso aos dados e à identificação do participante. Podemos ainda, em outro nível, interpretar como uma desconsideração da relevância do campo de investigação para a formação de futuros professores.

Conforme sinalizado previamente, as categorias do Gráfico 1 não estão separadas por fronteiras rígidas, podendo um participante expressar mais de uma visão. Portanto, dependendo do cunho analítico, o gráfico poderia apresentar proporções diferentes. Nesses casos, optamos por focalizar, em determinados participantes, a categoria que, a nosso ver, está mais enfatizada. No Gráfico 2, tentamos representar esse aspecto:

\section{GRÁFICO $2^{5}$}

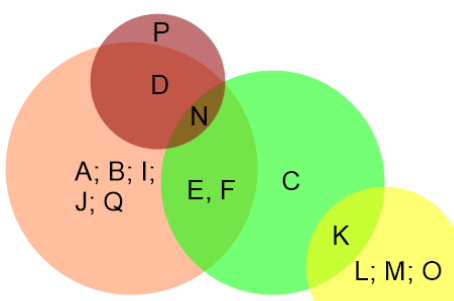

LA COMO SUBÁREA DA

LINGUÍSTICA

LA COMO MEDIADORA ENTRE

TEORIA E PRÁTICA

LA COMO ÁREA INTER/MULTI/PLURI

OU TRANSDISCIPLINAR

LA COMO ÁREA AUTÔNOMA

\footnotetext{
${ }^{5}$ Os participantes $\mathrm{G}$ e $\mathrm{H}$ não estão representados no gráfico, pois não se enquadram em nenhuma das categorias elencadas, devido às suas respostas (resposta em branco e "Prefiro não responder").
} 
Como é possível perceber a partir do Gráfico 2, no qual cada letra representa um dos participantes, os participantes E e F concebem a LA tanto como "subárea da linguística" quanto como área de "conhecimento não disciplinar". Fenômeno equivalente ocorre com o participante $\mathrm{N}$ que concebe, ao mesmo tempo, a área como "não disciplinar", "mediadora entre teoria e prática" e "subárea da linguística". O participante K, por sua vez, se encontra nas categorias "não disciplinar" e "área autônoma com foco na linguagem em contextos". Por fim, o participante D entende a LA como "subárea da Linguística" e como "mediadora entre teoria e prática". Em apenas uma categoria, foram situados os participantes A, B, I, J e Q ("LA como subárea da Linguística"); C ("LA como área não disciplinar"); L, M e O ("LA como área autônoma"); e P ("LA como mediadora entre teoria e prática”).

\subsubsection{LA compreendida como subárea da linguística}

A compreensão da LA como subárea da linguística, talvez a mais comum das interpretações, é a que reúne o maior número das respostas atribuídas pelos professores investigados (34\%). Isso talvez seja compreensível pelo fato de que, até mesmo agências nacionais de fomento à pesquisa, a exemplo do Conselho Nacional de Desenvolvimento Científico e Tecnológico (CNPq) e da Coordenação de Aperfeiçoamento de Pessoal de Nível Superior (CAPES), situam a LA nessa disposição. Essa visão pode ser entendida como reflexo da inserção dos formadores em um espaço em que a LA ocupa uma posição periférica. Segundo essa visão, a LA seria um apêndice da linguística, ocupando, portanto, posição inferior. Para Kleiman (1998, p. 52), esse modo de enxergar a LA “tem suas origens tanto na história das duas disciplinas quanto em fatores conjunturais do desenvolvimento atual da linguística". Talvez isso justifique o fato de, na licenciatura focalizada, a LA está inserida explicitamente como disciplina eletiva.

Essa compreensão de LA fica clara na resposta de um docente da licenciatura, reproduzida no Exemplo 1, e que poderia ocupar, no Gráfico I, a visão não disciplinar ("LA como área inter/multi/pluri ou transdisciplinar"); no entanto, a caracterização inicial nos pareceu mais acentuada ("subárea da Linguística"). Representação semelhante, observamos na resposta de outro formador, reproduzida no Exemplo 2, para o qual mantemos a mesma classificação. 


\section{Exemplo 01}

É um campo ou área da linguística interdisciplinar de estudo que busca investigar e identificar problemas relacionados com a língua, relacionados com a linguagem e pode envolver outros campos da educação, linguística, antropologia e sociologia etc. (Compreensão da LA - Participante E)

\section{Exemplo 02}

[...] um ramo dos estudos linguísticos direcionado à prática; um ramo complexo que abarca e se deixa abarcar por uma série grande de outras ramificações, tanto linguísticas quanto antropológicas, étnicas, históricas, geográficas e de outros estudos da mente. (Compreensão da LA - Participante F)

É importante destacar que a linguística, de modo geral, se preocupa com problemas relacionados à linguagem como sistema, pouco os relacionando com outros fatores que a constituem, embora algumas de suas subáreas tenham se desprendido dessas características. Já a LA considera como indissociáveis da linguagem os valores, ideologias, e singularidades dos sujeitos falantes.

A frágil relação entre estudos teóricos e práticas reais de uso da linguagem bem como a atribuição à LA de características mais comuns à Linguística foram aspectos bem retratados nas respostas dos formadores das licenciaturas quanto à importância de suas disciplinas para a formação de professores, como se vê nos excertos dos Exemplos 3 e 4.

\section{Exemplo 03}

[...] assim como a linguística, [a LA] serve para analisar, interpretar, estudar os fenômenos relativos à linguagem e comunicação. (Compreensão da LA Participante A)

\section{Exemplo 04}

É a ciência da linguagem presente no dia a dia do falante, em que se caracteriza a sua forma de expressão. (Compreensão da LA - Participante B)

No Exemplo 4, é interessante salientar que compreensão de cunho praticamente idêntico é direcionada à linguística, pelo mesmo formador participante: "é a ciência da linguagem que estuda a manifestação verbal 
do sujeito" (Participante B, Concepção de Linguística). Os formadores demonstram dificuldade para diferenciar as duas áreas ou para compreender suas especificidades, o que, de alguma forma, pode ser motivado pelo próprio nome "linguística aplicada".

\subsubsection{LA compreendida como mediadora entre teoria e prática}

Nessa visão, a LA é caracterizada pela função de mediar descrições teóricas e atividades práticas, que ainda permanecem distantes do campo de atuação do professor, podendo ser vista como significativa para as licenciaturas. Nesse sentido, nos termos de Celani (1992, p. 18), "a LA pressupõe a linguística; é uma atividade e, não estudo teórico, que usa os resultados de estudos teóricos" para aplicá-los. Nela, temos, de certa forma, outra/a mesma visão da LA como subárea da linguística, o que ainda era bastante acentuada nas discussões acadêmicas instauradas na década de 1990. Adiante, seguem os Exemplos 5 e 6 a respeito do assunto.

\section{Exemplo 05}

[LA] aplica-se aos estudos voltados para o ensino, contextos práticos, aplicação conjunta de teoria e prática (e vice-versa). (Compreensão de LA - Participante D)

\section{Exemplo 06}

Na minha concepção, a L.A. é uma área que surgiu da linguística geral e se destina à prática de teorias e saberes. Colocar em prática o conhecimento ou ainda o ensino desse pela prática. A aplicação do saber. (Compreensão de LA - Participante P)

Como podemos perceber, no Exemplo 5, o participante apresenta a LA com o papel de aplicar teoria e prática, ficando a atuação do linguista aplicado limitada ao ensino. No Exemplo 6, a ideia de mediação se apresenta de maneira mais enfática, pois, segundo o participante, a LA se destina a aplicar as teorias. Esses dois últimos exemplos são divergentes da concepção de Moita Lopes (1998, p. 114), para o qual os verdadeiros linguistas aplicados "se alinham à maneira de fazer LA defendida internacionalmente, e [...] não fazem LA de maneira periférica ao seu trabalho principal, mas de forma central e sistemática", ou seja, não se situam à margem das produções teóricas e não se envolvem na validação dessas. 
Em várias respostas apresentadas pelos formadores, a LA aparece como interdisciplinar e dependente da linguística. Além disso, enfatizam a aplicação de teorias na área do ensino de língua, ignorando as diversas áreas de atuação do linguista aplicado. É importante lembrar que, apesar de a LA não se configurar como mediadora, isso não significa que a área não prescinda de teorizações. Contudo, diferentemente do que muitos dos participantes entendem, essas teorizações geralmente não são providas pela linguística, mas são resultados dos entrecruzamentos disciplinares (MOITA LOPES, 2013a).

\subsubsection{LA compreendida como área não disciplinar}

Segundo Celani (1998, p. 131, 132), concordando com Durand (1993), "em uma postura multi/pluri/interdisciplinar, disciplinas plurais colaboram no estudo de um objeto, de um campo, de um objetivo, em situação de integração" e "uma visão transdisciplinar, no entanto, tenta destacar nessa colaboração de disciplinas um fio condutor e até mesmo uma filosofia epistemológica, a 'filosofia' da descoberta" (grifos da autora).

Poucos participantes $(22 \%)$ caracterizaram a LA a partir desses modos de fazer pesquisa. Vejamos a resposta de um formador reproduzida no Exemplo 7.

\section{Exemplo 07}

Área de estudos inter/trans/indisciplinar que problematiza o uso da linguagem a partir de uma situação social concreta. (Compreensão de LA - Participante K)

Para o formador colaborador, a LA se caracteriza pela interdisciplinaridade, pela transdisciplinaridade, pela indisciplinaridade, e pelo interesse em situações determinadas e reais de uso da linguagem. A referência à indisciplinaridade - concepção pela qual a LA vem se caracterizando mais recentemente (MOITA LOPES, 2006a; PENNYCOOK, 2001), por entender que o termo dá conta de muitas das especificidades do campo de estudo - é apresentada unicamente pelo participante responsável pelo Exemplo 7. Na perspectiva da não disciplinarização, reproduzimos ainda o Exemplo 8. 


\section{Exemplo 08}

Como uma área interdisciplinar e/ou transdisciplinar, pois, para problematizar seu objeto (a linguagem ou a língua em uso) apoia-se em olhares de outras disciplinas, de aspectos de outras áreas que afetam a linguagem. (Compreensão de LA - Participante C)

Essa fala do formador dialoga com a proposta do projeto político da licenciatura focalizada: "a responsabilidade de formar professores capazes de refletir teoricamente sobre a linguagem, utilizando para isso de subsídios de diferentes teorias e abordagens" (ARAGUAÍNA, 2009, p. 21). O excerto também é condizente com algumas concepções de LA compartilhadas por linguistas aplicados, conforme resenhamos previamente neste artigo. Outro formador, por exemplo, citou as seguintes disciplinas como interlocutoras mais imediatas da LA: educação, linguística, antropologia e sociologia. Ressaltamos, porém, que essa compreensão não disciplinar pode ser interpretada como representação da LA como área do conhecimento que precisa de amparo, sem subsídios próprios ou suficientes para a sua existência.

Podemos observar que muitas das respostas que identificam a LA como campo interdisciplinar parecem estacionadas numa noção de interdisciplinaridade ultrapassada ou não esclarecem a relação estabelecida entre as disciplinas. $\mathrm{Na} \mathrm{LA}$, essa relação só se justifica quando há um deslocamento, transformação ou mesmo uma produção de categorias teórico-metodológicas (SIGNORINI, 1998), o que, de certa forma, alinha essa relação à postura trans/indisciplinar assumida atualmente.

\subsubsection{LA como área autônoma com foco na linguagem}

Caracterizada como área autônoma do conhecimento, a LA seria responsável pela formulação dos próprios modelos teóricos, concentrandose na resolução de problemas sociais situados que envolvem a linguagem. Essa compreensão é bastante satisfatória diante do atual paradigma em construção da LA. Conforme Celani (1992, p. 15), "'a] própria aceitação de linguística aplicada como área de conhecimento de foro próprio não tem sido tarefa simples". A compreensão desse campo aplicado na perspectiva aqui focalizada pode ser vista no Exemplo 9. 


\section{Exemplo 09}

Ciência que tem conquistado seu espaço ao longo dos anos e que deixou de ser vista como mera aplicação de linguística para ser respeitada como possuidora de seus próprios métodos e objetos de pesquisa. Versa sobre o ensino e aprendizagem e estudos de língua em uso em contextos dentro e fora de sala de aula. (Compreensão de LA - Participante L)

\section{Exemplo 10}

A L.A. é uma área das ciências humanas que estuda a linguagem em contexto real de uso, ou seja, a linguagem em contexto social e histórico. (Compreensão de LA - Participante O)

Além do reconhecimento da LA como campo autônomo de estudos da linguagem, os formadores consideram a situacionalidade ou particularidade das pesquisas da LA, bem como a amplitude do seu escopo (Exemplo 10), não restringindo o papel do linguista aplicado a investigações referentes ao ensino e à aprendizagem de línguas, conforme visto no Exemplo 9: "[LA] versa sobre o ensino e aprendizagem e estudos de língua em uso em contextos dentro e fora de sala de aula". Moita Lopes (1998, p. 118, 119) chama a atenção para esse aspecto: "trata-se de conhecimento centrado na resolução de um problema de um contexto de aplicação específico [...]. Isto quer dizer que o tipo de conhecimento produzido é 'altamente contextualizado"”.

Conforme perceptível nas análises exemplificadas nesta seção, as compreensões partilhadas da natureza conceptual da LA são bastante difusas. Esclarecer essa diversidade e as implicações dessas concepções para as atividades de pesquisa e de ensino se faz necessário, especialmente para os docentes das licenciaturas responsáveis pela formação dos professores de língua.

\subsection{Compreensões da LA por professores em formação inicial}

Para investigarmos como os professores em formação inicial compreendem a LA, foi elaborado um questionário com as seguintes perguntas: (1) Você já ouviu falar sobre Linguística Aplicada na Licenciatura em Letras?; (2) Caso sua resposta para a questão anterior tenha sido positiva, explicite em quais situações você teve contato com a Linguística Aplicada 
na Licenciatura em Letras; (3) Como você concebe a Linguística Aplicada?; e (4) No seu ponto de vista, quais as contribuições da Linguística Aplicada para a sua formação na Licenciatura em Letras?

A aplicação do questionário ocorreu durante aulas de estágio supervisionado obrigatório, em turmas do $5^{\circ}$ ao $8^{\circ}$ períodos da licenciatura focalizada. Supervisionamos a aplicação dos questionários para evitar o acesso dos colaboradores a fontes bibliográficas ou a recursos tecnológicos com Internet. Além da afinidade da disciplina de estágio com a LA, nos períodos selecionados, os professores em formação inicial já alcançaram maior vivência na licenciatura, incluindo também alguma vivência na escola de ensino básico, futuro local de trabalho.

Tínhamos como meta aplicar o questionário com 60 alunos, em um total de seis turmas, variando entre a licenciatura em Língua Inglesa e a licenciatura em Língua Portuguesa, já que o campo de abrangência da LA compreende as habilitações ofertadas. A efetiva interação com os 60 alunos não foi alcançada, e apenas 42 responderam ao questionário, devido a algum receio existente em participar da pesquisa, justificando falta de conhecimento sobre o assunto tematizado.

O resultado do primeiro questionamento ("Você já ouviu falar sobre Linguística Aplicada na Licenciatura em Letras?") esteve dentro daquilo que esperávamos: dos 42 alunos entrevistados, 36, ou seja, 85,8\%, declararam já ter ouvido falar na LA, e apenas seis, $14,2 \%$, afirmaram nunca terem ouvido falar, o que, de alguma forma, revela o conhecimento da LA no ambiente da licenciatura.

$\mathrm{Na}$ segunda questão (“Caso sua resposta para a questão anterior tenha sido positiva, explicite em quais situações você teve contato com a Linguística Aplicada na Licenciatura em Letras"), procuramos compreender em quais situações os alunos tiveram contato com a LA. As respostas foram organizadas em quatro categorias: (1) alunos apenas ouviram falar em LA; (2) alunos ouviram falar em LA como disciplina eletiva; (3) alunos ouviram falar em LA durante disciplinas da licenciatura; e (4) alunos desconhecem a LA. O resultado reitera o compartilhamento do conhecimento elementar sobre a LA por parte dos professores em formação inicial, conforme observável na Tabela 1. 
TABELA 1

Contato com a LA

\begin{tabular}{|c|c|}
\hline CATEGORIA & PERCENTAGEM \\
\hline$(1)$ & $40 \%$ \\
\hline$(2)$ & $24 \%$ \\
\hline$(3)$ & $24 \%$ \\
\hline$(4)$ & $12 \%$ \\
\hline
\end{tabular}

Dentre os acadêmicos questionados, $40 \%$, ou seja, quinze professores em formação inicial declararam apenas ter ouvido falar em LA. Conforme os próprios entrevistados, esse contato se deu de maneira informal, por meio de conversas com outros acadêmicos e até mesmo com alguns formadores. Podemos pressupor que, para esses $40 \%$, a proximidade com a LA foi bastante tímida, visto que não cursaram a disciplina eletiva ofertada na licenciatura, resultando no compartilhamento de informações passadas informalmente. Nos exemplos do Quadro 1, reproduzimos algumas respostas representativas dessa categoria.

\section{QUADRO 1}

Ouviu falar da LA

\begin{tabular}{|c|l|}
\hline Exemplo & \multicolumn{1}{c|}{ Resposta } \\
\hline 11 & Por falares e por alguns professores. \\
\hline 12 & Eu apenas ouvi falar, mas não tive contato no momento. \\
\hline 13 & Não tive contato mais já ouvi falar. \\
\hline 14 & Já ouvi falar, mas não sei do que se trata. \\
\hline
\end{tabular}

Os professores em formação demonstram desconhecer o campo de atuação do linguista aplicado, bem como possíveis contribuições da LA para a formação de professores, em especial, no tocante a saberes produzidos no campo aplicado e que podem contribuir para o trabalho pedagógico no futuro espaço de atuação profissional. A ausência de informações mais precisas acerca da LA revela o desconhecimento discente a respeito das próprias disciplinas ofertadas na licenciatura cursada, restando-nos um questionamento: como escolher disciplinas eletivas para cursar sem o 
mínimo de conhecimento do conteúdo a ser focalizado? Esse fato justifica o desinteresse dos acadêmicos em cursar a LA como disciplina eletiva da licenciatura. Faltam informações para que eles percebam que essa disciplina pode contribuir para a formação do professor de língua materna ou adicional.

Dentre os professores em formação inicial, 24\% responderam conhecer a LA como uma disciplina eletiva na matriz curricular da licenciatura em Letras, conforme ilustrado nas respostas reproduzidas nos exemplos do Quadro 2. Desses colaboradores, alguns afirmaram ter cursado a disciplina no $7^{\circ}$ período da licenciatura.

\section{QUADRO 2}

LA como disciplina eletiva

\begin{tabular}{|c|l|}
\hline Exemplo & \multicolumn{1}{c|}{ Resposta } \\
\hline 15 & $\begin{array}{l}\text { Conheço como uma matéria optativa e que é o objeto de } \\
\text { estudo de alguns professores. }\end{array}$ \\
\hline 16 & $\begin{array}{l}\text { Meu contato deu-se somente com a estrutura curricular, na } \\
\text { qual há uma disciplina cujo nome é Linguística Aplicada. }\end{array}$ \\
\hline 17 & $\begin{array}{l}\text { Já ouvi falar como matéria optativa para o curso de } \\
\text { licenciatura em Letras, mas não conheço e não sei do que os } \\
\text { assuntos abordados tratam. }\end{array}$ \\
\hline
\end{tabular}

Como podemos observar no Quadro 2, o conhecimento compartilhado pelos professores em formação inicial corresponde ao simples fato de saber que a disciplina consta como eletiva no projeto pedagógico do curso de licenciatura e que há formadores do curso que desenvolvem pesquisa no âmbito da LA. Há indícios de desconhecimento pelos acadêmicos dos objetos de pesquisa investigados no âmbito da LA por docentes da licenciatura focalizada nesta pesquisa.

Dentre os acadêmicos questionados, $24 \%$ argumentaram conhecer LA por meio das disciplinas da licenciatura em Letras, a exemplo de: Introdução aos Estudos Linguísticos; Fonética e fonologia; Pragmática; Sintaxe; e Estágio, como observamos nas respostas reproduzidas nos exemplos do Quadro 3. 
QUADRO 3

LA tematizada em disciplinas da licenciatura

\begin{tabular}{|c|l|}
\hline Exemplo & \multicolumn{1}{c|}{ Resposta } \\
\hline 18 & $\begin{array}{l}\text { As minhas primeiras experiências com linguística se deram } \\
\text { por meio da disciplina Linguística Geral, na qual abordamos } \\
\text { Saussure e seus preceitos. Vimos também sintaxe, que punha } \\
\text { em foco também a linguística/gramática e suas interfaces. }\end{array}$ \\
\hline 19 & $\begin{array}{l}\text { No decorrer da graduação o contato com a Linguística } \\
\text { Aplicadaocorreu de formaimplícita explícita, principalmente } \\
\text { nas disciplinas de Estágio Supervisionado, Introdução aos } \\
\text { Estudos Linguísticos, Pragmática e Semiótica. }\end{array}$ \\
\hline
\end{tabular}

No Exemplo 18, evidenciamos que o professor em formação fala da linguística e não da LA, o que demonstra que há confusão entre as ciências: não se percebe que são disciplinas distintas. Já no Exemplo 19, o acadêmico está consciente do tema a que nos referimos e relata justamente o estágio supervisionado, que tem uma grande proximidade com a LA. Nas respostas para a questão focalizada, observamos que, quando o aluno declara que ouviu falar em LA em outras disciplinas, pode haver algum equívoco entre o tema elencado e a linguística, já que os nomes são bem parecidos. Acrescese a isso o fato de que por muito tempo perdurou a ideia de LA como mera aplicação da linguística, conforme vimos em seção anterior neste artigo.

Os demais acadêmicos questionados, somando $12 \%$, demonstraram maior desconhecimento da LA. As respostas evidenciaram total desconhecimento a respeito do assunto (Ex. "Negative"; "?"). Nesse momento, podemos ver que o caso se torna mais crítico, visto que os professores em formação inicial estão desinformados acerca do assunto tematizado. Parecem desconhecer, inclusive, a disciplina eletiva na matriz curricular da licenciatura. As demais disciplinas da licenciatura, inclusive os próprios estágios supervisionados, parecem não desencadear algum discernimento dos acadêmicos a respeito da LA.

Na terceira questão (“Como você concebe a Linguística Aplicada?”), procuramos verificar o que seria LA para esses professores em formação inicial. Deparamo-nos com variedades de respostas que entram em contradição com as respostas para as questões anteriores. A partir das respostas apresentadas, foram geradas as seguintes categorias analíticas: (1) desconhecem a LA; (2) concebem LA como linguística; e (3) conhecem a LA. 
TABELA 2

Compreensão da LA

\begin{tabular}{|c|c|}
\hline CATEGORIA & PERCENTAGEM \\
\hline$(1)$ & $48 \%$ \\
\hline$(2)$ & $28 \%$ \\
\hline$(3)$ & $24 \%$ \\
\hline
\end{tabular}

A maioria dos professores em formação inicial (48\%) afirmou não ter o mínimo conhecimento a respeito da LA. Essas respostas complementam os resultados gerados a partir das respostas para a primeira questão, focalizada no início desta subseção, quando $86 \%$ dos questionados disseram já ter ouvido falar em LA. Essa variação entre as respostas geradas mostra que ouvir falar em LA na licenciatura não significa compreender o propósito do campo aplicado dos estudos da linguagem. Ou seja, para muitos dos alunos da licenciatura, o contato com a LA aconteceu de maneira superficial. No Quadro 4, reproduzimos quatro exemplos para ilustrar as respostas apresentadas.

\section{QUADRO 4}

Desconhecimento da LA

\begin{tabular}{|c|l|}
\hline Exemplo & \multicolumn{1}{|c|}{ Resposta } \\
\hline 20 & $\begin{array}{l}\text { Não sei nada sobre ela, não tenho acesso a Linguística } \\
\text { Aplicada, portanto não concebo. }\end{array}$ \\
\hline 21 & Não sei conceituá-la. \\
\hline 22 & Não sei como explicar. \\
\hline 23 & $\begin{array}{l}\text { Ainda não sei explicar sobre essa disciplina. Não sei sobre o } \\
\text { que a disciplina aborda. }\end{array}$ \\
\hline
\end{tabular}

Dentre os professores em formação inicial, 28\% fizeram confusão entre LA e linguística, conforme ilustramos com as duas respostas reproduzidas nos exemplos do Quadro 5. 
QUADRO 5

Concepção da LA como linguística

\begin{tabular}{|c|l|}
\hline Exemplo & \multicolumn{1}{c|}{ Resposta } \\
\hline 24 & $\begin{array}{l}\text { A meu ver a LA estuda a forma como o falante, os participantes } \\
\text { se relacionam, como a transmissão do significado é feito. }\end{array}$ \\
\hline 25 & $\begin{array}{l}\text { Estuda a linguagem verbal, a gramática e a evolução dos } \\
\text { idiomas. }\end{array}$ \\
\hline
\end{tabular}

Dentre esses participantes, $24 \%$ souberam conceber LA de acordo com pressupostos teóricos defendidos por linguistas aplicados cujos trabalhos foram resenhados previamente neste artigo: uma LA transdisciplinar ou interdisciplinar (CELANI, 1998, 1992; KLEIMAN, 2002, 1998; MOITA LOPES, 1998, 1996). Os autores dessas respostas, ilustradas nos três exemplos reproduzidos no Quadro 6, são os colaboradores que informaram ter cursado a disciplina eletiva LA na licenciatura.

\section{QUADRO 6}

Conhecimento da LA

\begin{tabular}{|c|l|}
\hline Exemplo & \multicolumn{1}{|c|}{ Resposta } \\
\hline 26 & $\begin{array}{l}\text { Como um campo interdisciplinar de estudo que busca } \\
\text { identificar, investigar e oferecer soluções para problemas } \\
\text { relacionados com a linguagem em uso real. Além disso, a LA } \\
\text { é uma pesquisa aplicada que se preocupa principalmente em } \\
\text { resolver problemas de linguagem dentro e fora do ambiente } \\
\text { escolar. }\end{array}$ \\
\hline 27 & $\begin{array}{l}\text { A linguística aplicada é um campo de pesquisa científica } \\
\text { interdisciplinar e transdisciplinar que visa a identificar e a } \\
\text { solucionar problemáticas relacionadas à linguagem. }\end{array}$ \\
\hline 28 & $\begin{array}{l}\text { Como um referencial das demais linguísticas no sentido de } \\
\text { adequar o estudo às realidades com suas complicações. E uma } \\
\text { tentativa de abranger segmento governamental diacronicamente } \\
\text { para resolver o problema a partir da informação e do olhar } \\
\text { crítico dos que permeiam essa realidade (LA). }\end{array}$ \\
\hline
\end{tabular}

As respostas trazem compreensões que nos remetem a concepções defendidas por Moita Lopes (1996, p. 22), quando afirma compreender a LA “como uma área de investigação aplicada, mediadora interdisciplinar, 
centrada na resolução de problemas de uso da linguagem, que tem um foco na linguagem de natureza processual, que colabora com o avanço do conhecimento teórico".

A LA tem seus trabalhos voltados a investigações de problemas que envolvem a linguagem em uma forma ampla dentro e fora do contexto escolar, assim como destacado nas respostas do Quadro 6. Os estudos envolvendo os gêneros textuais ou discursivos, desenvolvidos por linguistas aplicados é um exemplo de que a LA está intrinsicamente inserida no contexto da formação de professores de línguas, pois contribui significativamente com teorias que orientam o professor a ministrar aulas, utilizando-se do gênero como um instrumento de interação e mediação, não apenas como uma forma ou modelo que deve ser aprendido (SILVA, 2015; 2012; SILVA, LIMA, MOREIRA, 2016).

$\mathrm{Na}$ última pergunta do questionário, indagamos dos colaboradores acerca das contribuições da LA para sua formação em Letras. Para essa questão, obtivemos quatro tipos de respostas: (1) desconhecem contribuições da LA; (2) LA descrita como importante; (3) contribuição da LA para aprendizado gramatical; e (4) contribuição da LA para a construção de um olhar crítico.

TABELA 3

Contribuições da LA

\begin{tabular}{|c|c|}
\hline CATEGORIA & PERCENTAGEM \\
\hline$(1)$ & $38 \%$ \\
\hline$(2)$ & $24 \%$ \\
\hline$(3)$ & $19 \%$ \\
\hline$(4)$ & $19 \%$ \\
\hline
\end{tabular}

Dentre os colaboradores, 38\% declararam não saber em que a LA contribui para a própria formação. Boa parte desses que desconhecem a contribuição da LA são os mesmos que informaram não a conhecer, ao se depararem com a primeira pergunta do questionário aplicado. Observando as respostas apresentadas (Ex.: "Não sei") e o quantitativo dos que desconhecem as contribuições da LA, somos levados a pensar, mais uma vez, sobre o discernimento dos acadêmicos no tocante ao percurso a ser 
construído na licenciatura. Ou seja, falta mais autonomia ao acadêmico durante a licenciatura.

Para 24\% dos colaboradores, a LA é um fator importante para a própria formação, ainda que não saibam em quais aspectos. Isto é, apesar dos acadêmicos não compreenderem quais as contribuições da LA, parecem reconhecer alguma relevância para sua formação pelo simples fato da oferta disciplinar na licenciatura, mesmo sendo componente curricular eletivo. No Quadro 7, reproduzimos algumas respostas como exemplo.

\section{QUADRO 7}

LA descrita como importante para formação do professor

\begin{tabular}{|c|l|}
\hline Exemplo & \multicolumn{1}{c|}{ Resposta } \\
\hline 29 & Creio que deve ser algo deveras importante. \\
\hline 30 & $\begin{array}{l}\text { Acredito que me ajudará bastante, mas não sei ao certo com } \\
\text { quais contribuições específicas. }\end{array}$ \\
\hline 31 & $\begin{array}{l}\text { Como eu ainda não tive contato, não sei falar muito; o que eu } \\
\text { sei é que deve ser muito importante, principalmente para nós } \\
\text { estudante de Letras. }\end{array}$ \\
\hline
\end{tabular}

Em 19\% das respostas, os colaboradores declararam que a LA é importante para que o professor venha a ter um domínio mais efetivo da gramática. Esses mesmos colaboradores, em perguntas anteriores, afirmaram que estudaram algo relativo à LA no primeiro período do curso, na disciplina Introdução aos Estudos Linguísticos. Os dados revelam, conforme ilustrado no Quadro 8, que os colaboradores fizeram distorções referentes ao propósito da LA. Entendemos que a LA não se ocupa diretamente da gramática da língua, mas pode trazer, por exemplo, contribuições efetivas para o estudo da gramática no ensino básico (SILVA, 2011; SILVA et al, 2015; SILVA; SILVA, 2016), estando voltada para o desenvolvimento crítico do professor e do aluno. 
QUADRO 8

Importância da LA para o aprendizado da gramática

\begin{tabular}{|c|l|}
\hline Exemplo & \multicolumn{1}{|c|}{ Resposta } \\
\hline 32 & $\begin{array}{l}\text { Provavelmente terá o foco no ensino. Como seremos } \\
\text { professores de língua portuguesa (materna), a linguística } \\
\text { aplicada será mais um instrumento de conhecimento. } \\
\text { Contribuições: conhecimento da gramática para repassar } \\
\text { futuramente. }\end{array}$ \\
\hline 33 & $\begin{array}{l}\text { Pelo pouco que entendo do conceito de linguística aplicada, } \\
\text { é aquela que estuda as gramáticas existentes em sua prática } \\
\text { e uso. }\end{array}$ \\
\hline 34 & $\begin{array}{l}\text { Até o momento vimos só linguagem normativa. E para } \\
\text { minha formação é bom pois estuda a forma verbal, estuda a } \\
\text { gramática, e assim usaremos melhor a forma culta. }\end{array}$ \\
\hline
\end{tabular}

Para outros 19\% dos colaboradores, a LA aparece como a possiblidade de um olhar mais crítico para o ensino de língua. É representada como um suporte para a educação, no qual é possível encontrar soluções para problemas presentes no ambiente escolar. No Quadro 9, reproduzimos duas respostas ilustrativas dessa categoria analítica.

\section{QUADRO 9}

Concepção da LA como linguística

\begin{tabular}{|c|l|}
\hline Exemplo & \multicolumn{1}{c|}{ Resposta } \\
\hline 35 & $\begin{array}{l}\text { A LA contribui para minha formação crítica enquanto pro- } \\
\text { fessor em formação inicial no que diz respeito ao ensino de } \\
\text { língua. Além de mostrar a divergência entre teoria e prática, } \\
\text { pois, em minha opinião, a LA parte da prática para a teoria. }\end{array}$ \\
\hline 36 & $\begin{array}{l}\text { A linguística aplicada me fez ter um olhar diferenciado acerca } \\
\text { da língua, pois ela sugere que primeiro é necessário se iden- } \\
\text { tificar um problema, e depois procurar formas e meios para } \\
\text { solucioná-lo e, se necessário, deve-se recorrer a outras áreas } \\
\text { do conhecimento, pois a língua é algo social que está interdis- } \\
\text { ciplinarmente ligado a diferentes campos. }\end{array}$ \\
\hline
\end{tabular}

Como é possível observar no questionário de pesquisa, foram abordadas questões de maneira interligadas, sendo que uma resposta acabava por implicar em outras. Logo no início, vimos que a maioria dos alunos já 
tinha ouvido falar em LA, e, ao final, percebemos que esse contato se dera, na maioria dos casos, de maneira superficial. Os alunos pouco conhecem a LA, fator esse preocupante, visto que, ao informar explicitamente o trabalho pedagógico dentro de uma licenciatura em língua, a LA deve ser mais bem abordada, afinal tem muitas contribuições para o desenvolvimento crítico do professor em formação inicial. Nas palavras de Celani (2008, p. 22),

a contribuição da LA na área de ensino/aprendizagem de línguas é vasta e direta. No que se refere à aprendizagem de língua materna, a alfabetização, o letramento, a relação entre linguagem e trabalho, a aquisição e desenvolvimento da linguagem são áreas que dependem diretamente dos avanços nas pesquisas em LA para seu desenvolvimento.

A análise dos dados revela que, em sua grande maioria, os professores em formação inicial, no contexto analisado, demonstram pouca compreensão sobre a LA, o que se configura como um problema que aponta para a maneira como esse campo de estudos aplicados é considerado na universidade, seja na formação de professores de línguas ou até mesmo nas licenciaturas diversas. De alguma forma, esse resultado reflete as compreensões imprecisas de LA compartilhadas pelos formadores da mesma licenciatura.

\section{Considerações finais}

O estudo realizado nos mostrou que debates conceptuais acerca da LA ainda consistem em tema atual e atividade necessária. As dificuldades de compreensão desse campo de estudos aplicados e de reconhecimento quanto a sua autonomia, enquanto área de pesquisa, pouco têm diminuído. Esse fato atualiza a convocação de Moita Lopes (1996) e de Celani (1992), no fim do século passado, para a discussão da temática, numa tentativa de colaboração com o desenvolvimento da LA.

As discussões conceptuais trazidas neste artigo são úteis para refletirmos a respeito dos currículos de formação de professores, muitas vezes construídos de modo unidirecional. Essas reflexões, por sua vez, trazem à tona a necessidade de uma abordagem que contemple a realidade atual da forma mais abrangente possível. Não visamos aqui a apresentação de um modelo ideal, mas sim de um paradigma de pesquisa que considere a linguagem em uma ótica multidirecional, dada a sua complexidade, e que viabiliza um entendimento aprofundado. 
É preciso levar em consideração que a licenciatura em Letras está formando professores de línguas e esses profissionais têm que estar aptos a lidar com as diversas situações interativas na sala de aula contemporânea, em constante transformação devido aos avanços tecnológicos, por exemplo.

Ao abarcar questões de natureza social, política, ideológica, identitária, cultural, dentre outras, a LA se pretende responsiva à vida social (MOITA LOPES, 2013b; 2006; KLEIMAN, 2013), envolvendo, no bojo das pesquisas nela desenvolvidas, sujeitos sócio-historicamente situados, engajados na linguagem enquanto prática social também situada, o que contribui para a formação e futura prática profissional de professores de línguas.

O currículo dos cursos de Licenciaturas em Letras não se constitui unicamente de interesses na formação inicial do professor, mas visa, por muitas vezes, à hegemonia política institucional e pessoal. É preciso, portanto, que se reflita sobre o que é, realmente, essencial para a formação docente, que se adeque o ensino às demandas atuais e que se compreenda as implicações políticas das escolhas realizadas no âmbito das licenciaturas e, também, das práticas desses futuros professores. É preciso, principalmente, levantar e ampliar pesquisas e discussões como esta para percebermos a vOz do linguista aplicado, dito humildemente, em pé de igualdade com outras vozes.

\section{Referências}

ARAGUAÍNA. Projeto pedagógico do curso: licenciatura em Letras: Língua Portuguesa e respectivas literaturas e Língua Inglesa e respectivas literaturas. Araguaína: UFT, 2009.

CELANI, M. A. A. Afinal, o que é linguística aplicada? In: PASCHOAL, M. S. Z.; CELANI, M. A. A. (Org.). Linguística aplicada: da aplicação linguística à linguística transdisciplinar. São Paulo: Educ, 1992. p. 15-23.

CELANI, M. A. A. Transdisciplinaridade na linguística aplicada no Brasil. In: SIGNORINI, I.; CAVALCANTI, M. C. (Org.). Linguística aplicada e transdisciplinaridade: questões e perspectivas. Campinas: Mercado de Letras, 1998. p. 129-142.

CELANI, M. A. A. A relevância da linguística aplicada na formação de uma política educacional brasileira. In: FORTKAMP, M. B. M.; TOMITCH, L. M. B. (Org.). Aspectos da linguistica aplicada: estudos em homenagem ao professor Hilário Inácio Bohn. 2. ed. Florianópolis: Insular, 2008. p. 17-32. 
CORACINI, M. J.; BERTOLDO, E. S. (Org.). O desejo da teoria e a contingência da prática: discursos sobre e na sala de aula (língua materna e língua estrangeira). Campinas: Mercado de Letras, 2003.

FORTKAMP, M. B. M.; TOMITCH, L. M. B. (Org.). Aspectos da linguística aplicada: estudos em homenagem ao professor Hilário Inácio Bohn. Florianópolis: Insular, 2008.

FREIRE, M. M.; ABRAHÃO, M. H. V.; BARCELOS, A. M. F. (Org.). Linguística aplicada \& contemporaneidade. Campinas: Pontes, 2005.

GONÇALVES, A. V.; SILVA, W. R.; GÓIS, M. L. de S. (Org.). Visibilizar a linguística aplicada: abordagens teóricas e metodológicas. Campinas: Pontes, 2014.

HALL, C. J.; SMITH, P. H.; WICAKSONO, R. (Eds.). Mapping applied linguistics: a guide for students and practitioners. London: Routledge, 2011.

KLEIMAN, A. B. O estatuto disciplinar da linguística aplicada: o traçado de um percurso, um rumo para o debate. In: SIGNORINI, I.; CAVALCANTI, M. C. (Org.). Linguistica aplicada e transdisciplinaridade: questões e perspectivas. Campinas: Mercado de Letras, 1998. p. 51-75.

KLEIMAN, A. B. A interface de questões éticas e metodologias na pesquisa em linguística aplicada. In: SILVA, D. E. G.; VIEIRA, J. A. (Org.). Análise do discurso: percursos teóricos e metodológicos. Brasília, DF: Plano, 2002. p. 187-202.

KLEIMAN, A. B. Agenda de pesquisa e ação em linguística aplicada: problematizações. In: MOITA LOPES, L. P. (Org.). Linguística aplicada na modernidade recente: festschrift para Antonieta Celani. São Paulo: Parábola, 2013. p. 39-58.

MARTINS, R. G. Concepções de linguística aplicada compartilhadas por professores de licenciaturas em Letras. 2015. Trabalho de Conclusão de Curso (Licenciatura em Letras: Língua Portuguesa) - Universidade Federal do Tocantins, Araguaína, 2015.

MASON, J. Qualitative researching. London: Sage, 1996.

MOITA LOPES, L. P. Oficina de linguística aplicada: a natureza social e educacional dos processos de ensino/aprendizagem de línguas. Campinas: Mercado de Letras, 1996. (Coleção Letramento, Educação e Sociedade).

MOITA LOPES, L. P. A transdisciplinaridade é possível em linguística aplicada? In: SIGNORINI, I.; CAVALCANTI, M. C. (Org.). Linguistica aplicada e transdisciplinaridade: questões e perspectivas. Campinas: Mercado de Letras, 1998. p. 113-127.

MOITA LOPES, L. P. Fotografias da linguística aplicada no campo de línguas estrangeiras no Brasil. Documentação de Estudos em Linguistica Teórica e AplicadaDELTA, São Paulo, v. 15, p. 419-435, 1999. Número especial.

MOITA LOPES, L. P. (Org.). Por uma linguística aplicada indisciplinar. São Paulo: Parábola, 2006a. 
MOITA LOPES, L. P. Linguistica aplicada na modernidade recente: festschrift para Antonieta Celani. São Paulo: Parábola, 2013a.

MOITA LOPES, L. P. Gênero, sexualidade, raça em contextos de letramentos escolares. In: MOITA LOPES, L. P. (Org.). Linguística aplicada na modernidade recente: festschrift para Antonieta Celani. São Paulo: Parábola, 2013b. p. 227-247.

PENNYCOOK, A. Critical applied linguistics: a critical introduction. New York: Routledge, 2001.

SIGNORINI, I. Do residual ao múltiplo e ao complexo: o objeto da pesquisa em linguística aplicada. In: SIGNORINI, I.; CAVALCANTI, M. C. (Org.). Linguística aplicada e transdisciplinaridade: questões e perspectivas. Campinas: Mercado de Letras, 1998. p. 99-110.

SIGNORINI, I.; CAVALCANTI, M. C. (Org.). Linguistica aplicada e transdisciplinaridade: questões e perspectivas. Campinas: Mercado de Letras, 1998.

SANTOS, S. A. Concepções de linguística aplicada para alunos de uma licenciatura Letras. 2015. Trabalho de Conclusão de Curso (Licenciatura em Letras: Língua Portuguesa) - Universidade Federal do Tocantins, Araguaína, 2015.

SILVA, W. R. Gêneros em práticas escolares de linguagens: currículo e formação do professor. Revista Brasileira de Linguística Aplicada, Belo Horizonte, v. 15, n. 4, p. 1023-1055, 2015.

SILVA, W. R. Gêneros textuais em aulas de Língua Portuguesa no Ensino Médio brasileiro. Linguagem \& Ensino, Pelotas, v. 15, n. 2, p. 387-418, 2012.

SILVA, W. R. Estudo da gramática no texto: demandas para o ensino e a formação do professor de língua materna. Maringá: Eduem, 2011.

SILVA, W. R. et al. Linguística sistêmico-funcional na sala de aula. Raído, Dourados, v. 9, n. 18, p. 137-172, 2015.

SILVA, W. R.; LIMA, P. da S.; MOREIRA, T. M. (Org.). Gêneros na prática pedagógica: diálogos entre escolas e universidades. Campinas: Pontes, 2016.

SILVA, W. R.; PEREIRA, B. G. Estágio supervisionado como componente curricular catalisador de saberes na formação inicial do professor. Dominios de Lingu@gem, Uberlândia, v. 10, n. 1, p. 146-165, 2016.

SILVA, W. R.; SILVA, C. Análise linguística no ensino de língua materna: uma abordagem sistêmico-funcional. Calidoscópio, São Leopoldo, v. 14, n. 3, 2016. No prelo.

Data de submissão: 29/03/2016. Data de aprovação: 24/08/2016. 